\title{
Cervical Spinal Erythropoietin Induces Phrenic Motor Facilitation via Extracellular Signal-Regulated Protein Kinase and Akt Signaling
}

\author{
Erica A. Dale, ${ }^{*}$ Irawan Satriotomo, ${ }^{\star}$ and Gordon S. Mitchell \\ Department of Comparative Biosciences, University of Wisconsin, Madison, Wisconsin 53706
}

\begin{abstract}
Erythropoietin (EPO) is typically known for its role in erythropoiesis but is also a potent neurotrophic/neuroprotective factor for spinal motor neurons. Another trophic factor regulated by hypoxia-inducible factor-1, vascular endothelial growth factor (VEGF), signals via ERK and Akt activation to elicit long-lasting phrenic motor facilitation (pMF). Because EPO also signals via ERK and Akt activation, we tested the hypothesis that EPO elicits similar pMF. Using retrograde labeling and immunohistochemical techniques, we demonstrate in adult, male, Sprague Dawley rats that EPO and its receptor, EPO-R, are expressed in identified phrenic motor neurons. Intrathecal EPO at C4 elicits long-lasting pMF; integrated phrenic nerve burst amplitude increased $>90$ min after injection ( $63 \pm 12 \%$ baseline 90 min after injection; $p<0.001$ ). EPO increased phosphorylation (and presumed activation) of ERK (1.6-fold vs controls; $p<0.05$ ) in phrenic motor neurons; EPO also increased pAkt (1.6-fold vs controls; $p<0.05$ ). EPO-induced pMF was abolished by the MEK/ERK inhibitor U0126 [1,4-diamino-2,3-dicyano-1,4-bis(o-aminophenylmercapto)butadiene] and the phosphatidylinositol 3-kinase/Akt inhibitor LY294002 [2-(4-morpholinyl)-8-phenyl-1(4H)-benzopyran-4-one], demonstrating that ERK MAP kinases and Akt are both required for EPOinduced pMF. Pretreatment with U0126 and LY294002 decreased both pERK and pAkt in phrenic motor neurons $(p<0.05)$, indicating a complex interaction between these kinases. We conclude that EPO elicits spinal plasticity in respiratory motor control. Because EPO expression is hypoxia sensitive, it may play a role in respiratory plasticity in conditions of prolonged or recurrent low oxygen.
\end{abstract}

\section{Introduction}

The neural network controlling breathing uses multiple strategies to maintain an adequate oxygen supply, including negative feedback, feedforward, and adaptive control strategies (i.e., neuroplasticity; Mitchell and Johnson, 2003). Growth/trophic factors play key roles in many forms of respiratory plasticity (Mitchell and Johnson, 2003; Golder, 2008; Spedding and Gressens, 2008). For example, new synthesis of brain-derived neurotrophic factor (BDNF) and activation of its high-affinity receptor underlie a form of spinal respiratory plasticity: phrenic long-term facilitation (pLTF) after acute intermittent hypoxia (Fuller et al., 2000; Baker-Herman et al., 2004). Although BDNF signals via ERK MAP kinases and Akt (Reichardt, 2006; Golder, 2008), only ERK activation is required for pLTF (M. S. Hoffman and G. S. Mitchell, unpublished observations).

Vascular endothelial growth factor (VEGF) is a hypoxiasensitive growth/trophic factor (Liu et al., 1995; Forsythe et al., 1996) originally known for its angiogenic (Connolly et al., 1989)

\footnotetext{
Received July 28, 2011; revised Feb. 8, 2012; accepted March 7, 2012.

Author contributions: G.S.M. designed research; E.A.D. and I.S. performed research; E.A.D. and I.S. analyzed data; E.A.D. wrote the paper.

This work was supported by National Institutes of Health Grant NS057778. We thank Dr. S. Mahamed for his custom software that aided the analysis of neurophysiological recordings.

*E.A.D. and I.S. contributed equally to this work.

Correspondence should be addressed to Gordon S. Mitchell, Department of Comparative Biosciences, University of Wisconsin, 2015 Linden Drive, Madison, WI 53706. E-mail: mitchell@svm.vetmed.wisc.edu.

DOI:10.1523/JNEUROSCI.3873-11.2012

Copyright $\odot 2012$ the authors $\quad 0270-6474 / 12 / 325973-11 \$ 15.00 / 0$
}

and cell permeabilization (Senger et al., 1986) properties. Spinal VEGF receptor activation elicits long-lasting phrenic motor facilitation (pMF) via an ERK- and Akt-dependent mechanism (Dale-Nagle et al., 2011).

Erythropoietin (EPO) is another hypoxia-sensitive protein with hematopoietic properties (Bert, 1882; Bert, 1878; Jourdanet, 1875). EPO and its receptor (EPO-R) are expressed in the mammalian CNS (Masuda et al., 1994; Digicaylioglu et al., 1995; Marti et al., 1996; Morishita et al., 1997; Bernaudin et al., 1999; Brines et al., 2000; Juul, 2000), in which they are regulated by hypoxiainducible factor-1 (HIF-1 $\alpha$ ) (Semenza et al., 1991; Wang and Semenza, 1995; Wang et al., 1995); recent evidence suggests additional regulation via HIF-2 $\alpha$ (Yeo et al., 2008). EPO induces hippocampal synaptic plasticity (Weber et al., 2002), including long-term potentiation (Adamcio et al., 2008), and is neuroprotective for hippocampal (Sirén et al., 2001; Xiong et al., 2010) and motor (Celik et al., 2002; Iwasaki et al., 2002; Mennini et al., 2006; Koh et al., 2007; Nagańska et al., 2010) neurons. EPO-induced neuroprotection is ERK and Akt dependent (Kilic et al., 2005; Zhang et al., 2006; Shen et al., 2010), consistent with known downstream signaling from EPO-R activation (Gobert et al., 1995; Bao et al., 1999).

EPO modulates breathing via actions on peripheral chemoreceptors and brainstem respiratory neurons (Soliz et al., 2005, 2007a) and contributes to ventilatory acclimatization to chronic hypoxia (Gassmann and Soliz, 2009; Gassmann et al., 2009). Soluble EPO-R is a negative regulator of EPO binding that attenuates ventilatory acclimatization (Powell et al., 1998), demonstrating 
long-lasting EPO effects on the control of breathing (Soliz et al., 2007b). The impact of spinal EPO on the control of breathing has not been investigated previously.

Because EPO signals via ERK (Miura et al., 1994a; Gobert et al., 1995) and/or Akt (Damen et al., 1993; He et al., 1993; Mayeux et al., 1993; Miura et al., 1994b), we tested the hypotheses that (1) spinal EPO-R activation elicits pMF, (2) EPO and EPO-Rs are expressed in phrenic motor neurons, (3) spinal EPO increases phosphorylation of downstream signaling molecules in phrenic motor neurons (e.g., ERK and Akt), and (4) EPO-induced pMF requires spinal ERK and Akt activity.

\section{Materials and Methods}

Experimental animals

Three to 5-month-old adult male Sprague Dawley rats (colony 218A; Harlan) were used for all experiments. Animals were double housed with food and water ad libitum in a temperature- and light-controlled environment (12 h light/dark cycle, daily humidity and temperature monitoring). All protocols were approved by The Institutional Animal Care and Use Committee at the University of Wisconsin.

\section{Immunohistochemical experiments}

Retrograde labeling of phrenic motor neurons. To identify phrenic motor neurons, 12 rats were used for retrograde labeling with cholera toxin B (CtB) subunit via intrapleural injection (Mantilla et al., 2009). Isoflurane anesthesia was induced in a closed chamber and maintained via nose cone (1.5\% isoflurane in $100 \%$ oxygen). A total of $25 \mu \mathrm{l}$ of $0.5 \%$ CtB subunit (dissolved in $0.9 \%$ sterile saline; List Biological Laboratories) was injected into the right and left thoracic cavities $(6 \mathrm{~mm}$ deep, fifth intercostal space) using a $25 \mu \mathrm{l}$ Hamilton syringe and a custom-made needle ( $6 \mathrm{~mm}, 23 \mathrm{~g}$, semi-blunt). Rats were monitored for signs of respiratory compromise, but none were evident. Three days after surgery, the rats were anesthetized with isoflurane and prepared for intrathecal drug injections (see below).

$E P O$ and EPO-R immunostaining. Naive rats $(n=5)$ were killed with an overdose of Beuthanasia $(0.3 \mathrm{ml}$, i.p.) and perfused transcardially with ice-cold 0.01 м PBS, pH 7.4, followed by $4 \%$ buffered paraformaldehyde. Cervical spinal cords were excised, postfixed overnight, and cryoprotected in $30 \%$ sucrose at $4^{\circ} \mathrm{C}$ until they sank. Transverse sections $(40 \mu \mathrm{m})$ of $\mathrm{C} 4-\mathrm{C} 5$ ventral horn (including the phrenic motor nucleus) were cut using a freezing microtome (Leica SM 200R). In brief, free-floating sections were washed in $0.1 \mathrm{M}$ Tris-buffered saline with $0.1 \%$ Triton X-100 (TBS-Tx; three times for $5 \mathrm{~min}$ ) and incubated in TBS containing 1\% $\mathrm{H}_{2} \mathrm{O}_{2}$ for $30 \mathrm{~min}$. After washing (three times for $5 \mathrm{~min}$ ) in TBS-Tx, tissues were blocked with $5 \%$ normal goat serum at room temperature (RT) for $60 \mathrm{~min}$. Staining was performed by incubating sections with rabbit polyclonal anti-EPO (H-162; 1:500; Santa Cruz Biotechnology) or antiEPO-R (C-20; 1:500; Santa Cruz Biotechnology) at $4^{\circ} \mathrm{C}$ overnight. Both EPO and EPO-R antibodies are widely used, and their specificity has been tested in previous studies (Anderson et al., 2009; Sanchez et al., 2009; Mazur et al., 2010; Wu et al., 2010). The sections were washed in TBS-Tx and incubated in biotinylated secondary goat anti-rabbit antibody (1: 1000; Vector Laboratories). Conjugation with avidin-biotin complex (Vecstatin Elite ABC kit; Vector Laboratories) was followed by visualization with $3,3^{\prime}$-diaminobenzidine hydrogen peroxidase (DAB) (Vector Laboratories) according to the instructions of the manufacturer. Sections were washed in TBS, placed on gelatin-coated slides, dried, dehydrated in a graded alcohol series, cleared with xylenes, and mounted with Eukitt medium.

To localize EPO and EPO-R in phrenic motor neurons, free-floating sections from CtB-injected rats were washed in TBS-Tx (three times for 5 $\mathrm{min}$ ) and blocked with 5\% normal donkey serum (NDS) at RT for 60 min. Staining was performed by incubating sections with either rabbit polyclonal anti-EPO (H-162; 1:200; Santa Cruz Biotechnology) or rabbit EPO-R (C-20; 1:200; Santa Cruz Biotechnology) with anti-CtB antibody (Nondenatured Cholera Toxin B; goat polyclonal; 1:10,000; Calbiochem) at $4^{\circ} \mathrm{C}$ overnight. The sections were washed in TBS-Tx (three times for $5 \mathrm{~min}$ ) and incubated in conjugated donkey anti-rabbit green fluorescent Alexa Fluor 488 (1:500; Invitrogen) or donkey anti-rabbit green fluorescent Alexa Fluor 488 (1:500; Invitrogen) and donkey antigoat red fluorescent Alexa Fluor 594 (1:500; Invitrogen). Stained tissues were mounted under glass using anti-fade solution (Prolong Gold antifade reagent; Invitrogen). All images were captured and analyzed with a digital camera (Qcapture Pro 6.0; QImaging). Photomicrographs were created with Adobe Photoshop software (Adobe Systems).

All images presented in the figures received equivalent adjustments to brightness/contrast and exposure. Semiquantitative analysis (see below) was performed in a blinded manner before making any adjustments for white balance, gain, gamma, or offset. Sections incubated without primary or secondary antibodies or served as negative controls.

Intrathecal EPO injections. After induction in a closed chamber, isoflurane anesthesia was maintained initially via nose cone. The rats were then tracheotomized and pump ventilated $(2.5 \mathrm{ml}$; Rodent Ventilator, model 683; Harvard Apparatus), and isoflurane anesthesia was continued through the ventilator for the duration of surgery $(3.5 \%$ isoflurane in $50 \% \mathrm{O}_{2}$ ). After completion of surgery, rats were converted to urethane anesthesia via injection into a tail vein catheter $(1.8 \mathrm{~g} / \mathrm{kg})$. To replicate the surgical preparation during neurophysiological experiments (see below), rats received bilateral vagotomy, the femoral artery was tied off, and phrenic and hypoglossal nerves were transected. An intrathecal silicone catheter (2 French; Access Technologies) was placed with the tip on the dorsal surface of $\mathrm{C} 4$ after a $\mathrm{C} 2$ laminectomy and durotomy. Pancuronium bromide $(2.5 \mathrm{mg} / \mathrm{kg}$, i.v. $)$ was used to induce paralysis. Body temperature was maintained within $1^{\circ} \mathrm{C}$ of the initial measurement (rectal probe; Traceable; Thermo Fisher Scientific) with a custom built, temperature-controlled surgical table. PETCO $_{2}$ was maintained between 41 and $44 \mathrm{mmHg}$ as measured with a flow-through capnograph with sufficient response time to measure end-tidal $\mathrm{CO}_{2}$ in rats (Capnogard; Novametrix). Rats received one of four intrathecal drug treatments: (1) $10 \mu \mathrm{l}$ of EPO (recombinant human; tissue culture grade; doses ranged from 4 to 30 international units; R \& D Systems) dissolved in $0.1 \%$ bovine serum albumen (BSA) and artificial CSF (aCSF) (in mm: $120 \mathrm{NaCl}, 3 \mathrm{KCl}, 2 \mathrm{CaCl}, 2 \mathrm{MgCl}, 23 \mathrm{NaHCO}_{3}$, and 10 glucose bubbled with $\mathrm{CO}_{2}$ ); (2) $12 \mu \mathrm{l}$ of U0126 [1,4-diamino-2,3-dicyano1,4-bis (o-aminophenylmercapto)butadiene], an MEK inhibitor (dissolved in $100 \%$ DMSO and diluted with aCSF to a final concentration of $100 \mathrm{~mm}$ in 20\% DMSO; Promega) before EPO; (3) $12 \mu \mathrm{l}$ of LY294002 [2-(4morpholinyl)-8-phenyl-1(4H)-benzopyran-4-one], a phosphatidylinositol 3-kinase (PI3K) inhibitor (dissolved in 100\% DMSO and diluted with aCSF to a final concentration of $100 \mathrm{~mm}$ in 20\% DMSO; Tocris Bioscience) before EPO; or (4) $10 \mu \mathrm{l}$ of $0.1 \% \mathrm{BSA}$ in aCSF. After $15 \mathrm{~min}$, rats were perfused and fixed for phospho-ERK and phospho-Akt immunohistochemistry.

Phospho-ERK, phospho-Akt, and CtB immunostaining. To identify ERK and Akt phosphorylation in the phrenic motor nucleus after intrathecal EPO, with or without inhibitors of MEK (U0126) or PI3K (LY294002), C4-C5 spinal tissues from CtB-injected rats were blocked in NDS for $60 \mathrm{~min}$ and then incubated in phospho-ERK (1:500; Cell Signaling Technologies) or phospho-Akt antibodies (1:500, Cell Signaling Technologies) at $4^{\circ} \mathrm{C}$ overnight. The sections were washed in TBS-Tx and incubated in biotinylated secondary donkey anti-rabbit antibody (1:1000; Jackson ImmunoResearch). Conjugation with avidin-biotin complex (Vecstatin Elite ABC kit; Vector Laboratories) was followed by visualization with $\mathrm{DAB}$ (Vector Laboratories) according to the instructions of the manufacturer. After washing with TBS-Tx (three times for 5 $\mathrm{min}$ ), tissues were labeled with anti-CtB antibody (non-denatured CtB; goat polyclonal; 1:10,000; Calbiochem) overnight. The tissues were then incubated in conjugated donkey anti-goat red fluorescent Alexa Fluor 488 (1:500; Invitrogen) at RT for $60 \mathrm{~min}$ to visualize CtB. Stained tissues were mounted under glass using anti-fade solution (Prolong Gold antifade reagent; Invitrogen). Phospho-ERK and phospho-Akt protein expression (brown) were examined in CtB back-labeled phrenic motor neurons (green) with an epifluorescence microscope (Nikon).

Quantification and analysis of photomicrographs. Eight sections from each rat ( $n=3$ rats per group) at the C4-C5 segmental level were used for investigator-blinded immunohistochemical analyses. Phrenic motor neurons were identified as a cluster of large, fluorescing neurons in the mediolateral C4 ventral horn (Boulenguez et al., 2007; Mantilla et al., 2009; Dale-Nagle et al., 2011). Digital photomicrographs of immunore- 

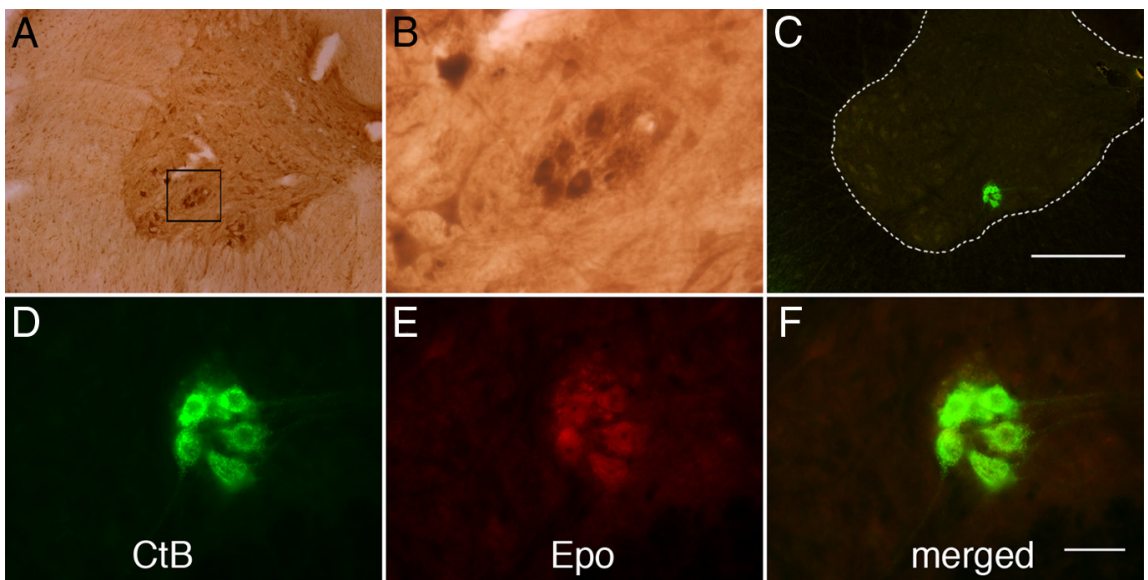

Figure 1. Representative images of EPO immunostaining in ( 4 phrenic motor neurons. $A, D A B$ staining revealed EPO expression in large, putative phrenic motor neurons (black box) and possible interneurons. B, Higher magnification of black box from A. C, CtB was intrapleurally injected to localize phrenic motor neurons (green cells in ventral horn). Scale bar (in $\boldsymbol{C}$ ), $400 \mu \mathrm{m}$. $\boldsymbol{D}-\boldsymbol{F}$, EPO (E) is expressed in (tB-labeled phrenic motor neurons (see merged image, $\boldsymbol{D}$ ) and surrounding neuropil. Scale bar (in $\boldsymbol{F}$ ), $50 \mu \mathrm{m}$.
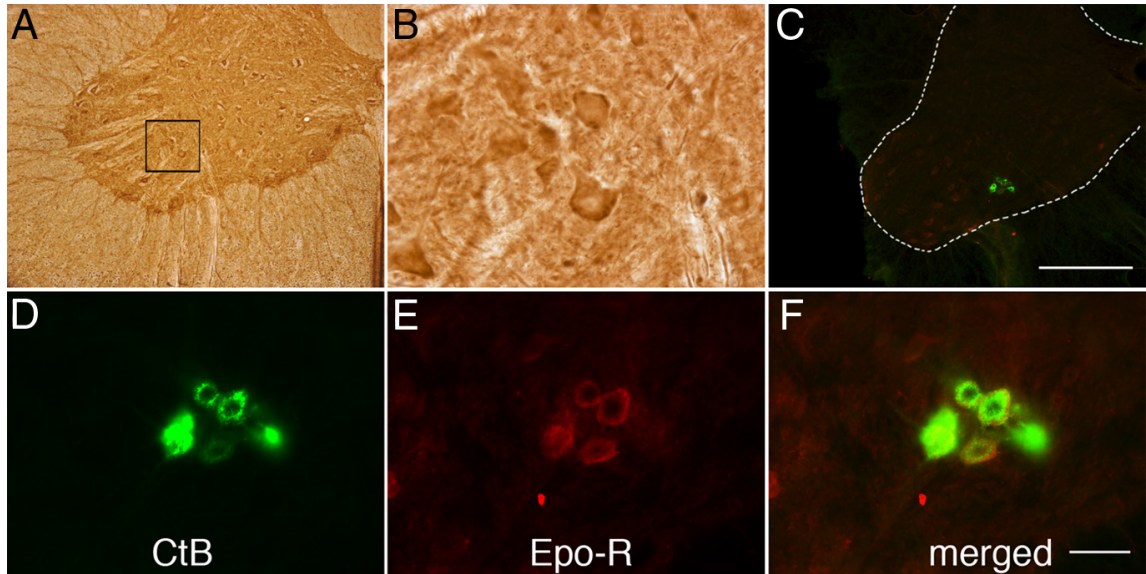

Figure 2. Representative images of EPO-R immunostaining in (4 phrenic motor neurons. $A$, DAB staining revealed EPO-R expression in large, putative phrenic motor neurons (black box) and interneurons. $\boldsymbol{B}$, Higher magnification of black bock from $\boldsymbol{A}$. $\boldsymbol{C}$, CtB-labeled phrenic motor neurons (green cells in (4 ventral horn). Scale bar (in $\boldsymbol{C}$ ), $400 \mu \mathrm{m}$. $\boldsymbol{D}-\boldsymbol{F}$, EPO-R (E) is expressed in CtB-labeled phrenic motor neurons ( $\boldsymbol{D}$; see merged image in $\boldsymbol{F}$ ) and the surrounding neuropil. Sections were incubated without primary or secondary antibody as negative controls. Scale bar (in $\boldsymbol{F}$ ), $50 \mu \mathrm{m}$.

active labeling in the region of the phrenic motor nucleus were taken with the 20× objective lens (Qcapture Pro 6.0; QImaging). Densitometry was performed by circumscribing the phrenic motor nucleus based on CtB labeling and determining the intensity of phospho-ERK and phosphoAkt immunostaining using NIH ImageJ software (http://rsb.info.nih.gov/ ij). Images were converted to eight-bit resolution, and the threshold was set between 120 and 160 during all analyses. The optical density $(O D)$ was measured within circumscribed phrenic motor neurons and expressed as an average OD per unit area for each individual cell. For each cell, the OD of phospho-ERK and phospho-Akt immunoreactivity was expressed as a fraction of the average OD of all cells in vehicle-treated rats. Thus, the mean OD in control rats is expected to be 1.0 , with a variance that reflects variations among cells within group. In EPO-treated rats, the OD was expressed as a ratio to the average of vehicle-treated cells. This normalized OD served as a measure of relative protein concentration of phospho-ERK and phospho-Akt within CtB-labeled cells. Data were compared between treatment groups using one-way ANOVA. Differences were considered significant if $p<0.05$. All values are expressed as means \pm 1 SEM

\section{Neurophysiology experiments}

Surgical preparation. Isoflurane anesthesia (3.5\% isoflurane in $50 \% \mathrm{O}_{2}$ ) was induced in a closed chamber and maintained with a nose cone. Rats were tracheotomized and pump ventilated $(2.5$ ml; Rodent Ventilator, model 683; Harvard Apparatus). After surgery, rats were slowly converted to urethane anesthesia $(1.8 \mathrm{~g} / \mathrm{kg})$ via tail vein catheter. To eliminate pulmonary stretch-receptor feedback and, thus, entrainment of respiratory activity with the ventilator, bilateral vagotomy was performed. Arterial blood taken via femoral artery catheterization enabled blood gas analysis throughout the experiment. After C2 laminectomy and durotomy, one or two intrathecal silicone catheters (2 French; Access Technologies) were placed with their tips resting on the dorsal surface of the $\mathrm{C} 4$ spinal segment. The left phrenic nerve was isolated via dorsal approach, cut distally, desheathed, submerged in mineral oil, and placed on bipolar silver electrodes. Rats were paralyzed with pancuronium bromide $(2.5 \mathrm{mg} / \mathrm{kg}$, i.v. $)$ after confirming adequate anesthesia (no purposeful movements or cardiorespiratory responses to toe pinch). Body temperature was measured with a rectal probe (Traceable; Thermo Fisher Scientific) and maintained within $\pm 1.0^{\circ} \mathrm{C}$ of baseline temperature via a custom-built, temperaturecontrolled surgical table. A flow-through capnograph with a sufficient response time to measure end-tidal $\mathrm{CO}_{2}$ in rats (Capnogard; Novametrix) was used to acquire end-tidal $\mathrm{CO}_{2}$. Blood samples were drawn at specified times into a heparinized plastic capillary tube $(250 \times 125 \mu \mathrm{l}$ cut in half; Radiometer Medical) to monitor arterial blood gases $\left(\mathrm{PaO}_{2}\right.$ and $\left.\mathrm{PaCO}_{2}\right), \mathrm{pH}$, and base excess (ABL 800Flex; Radiometer Medical). Blood pressure and acid/base balance were maintained via continuous intravenous fluid infusion (1: 3.75:3 by volume of $\mathrm{NaHCO}_{3}$ /lactated Ringer's/ Hetastarch; $1.5-2.2 \mathrm{ml} / \mathrm{h}$ ).

Phrenic nerve activity was amplified $(10,000$ $\times$; A-M Systems), bandpass filtered $(100 \mathrm{~Hz}$ to 10 $\mathrm{kHz}$ ), rectified, processed with a moving averager (CWE 821 filter; time constant, $50 \mathrm{~ms}$ ), and sampled at a rate of $4 \mathrm{kHz}$. WINDAQ dataacquisition system (DATAQ Instruments) was used to analyze the digitized, integrated signal. Peak integrated phrenic burst frequency and amplitude and mean arterial pressure were analyzed in $60 \mathrm{~s}$ bins directly before blood samples were taken. Data were included only if $\mathrm{PaCO}_{2}$ was maintained within $\pm 1.5 \mathrm{mmHg}$ of baseline, base excess was within \pm 5 of baseline, and the change in mean arterial pressure from the beginning to the end of a protocol was $<30 \mathrm{mmHg}$. Frequency data and nerve burst amplitudes are expressed as percentage change from baseline.

The apneic threshold (the $\mathrm{CO}_{2}$ level at which neural signals cease to fire) was determined at least $1 \mathrm{~h}$ after conversion to urethane anesthesia by decreasing inspired $\mathrm{CO}_{2}$ and/or increasing ventilator frequency. Baseline was established by maintaining end-tidal $\mathrm{PCO}_{2}$ between 1 and 2 mmHg above the phrenic burst recruitment threshold (the $\mathrm{PaCO}_{2}$ at which respiratory activity resumes; Bach and Mitchell, 1996). Baseline blood was drawn after $25 \mathrm{~min}$ of stable nerve recordings to establish a point of comparison for subsequent blood gas measurements. The rats then received one of six treatments (outlined below), and arterial blood samples were taken 15, 30, 60, and 90 min after intrathecal injections. All electrophysiological data were analyzed with a repeated-measures, twoway ANOVA (SigmaStat 2.03).

Drug administration. Six treatment protocols were used in the electrophysiological study: (1) $10 \mu \mathrm{l}$ of EPO (recombinant human; tissue culture grade; doses ranged from 4 to 30 international units; R \& D Systems) dissolved in $0.1 \% \mathrm{BSA}$ and aCSF (in mM: $120 \mathrm{NaCl}, 3 \mathrm{KCl}, 2 \mathrm{CaCl}, 2$ $\mathrm{MgCl}, 23 \mathrm{NaHCO}_{3}$, and 10 glucose bubbled with $\mathrm{CO}_{2}$ ); (2) $12 \mu \mathrm{l}$ of 


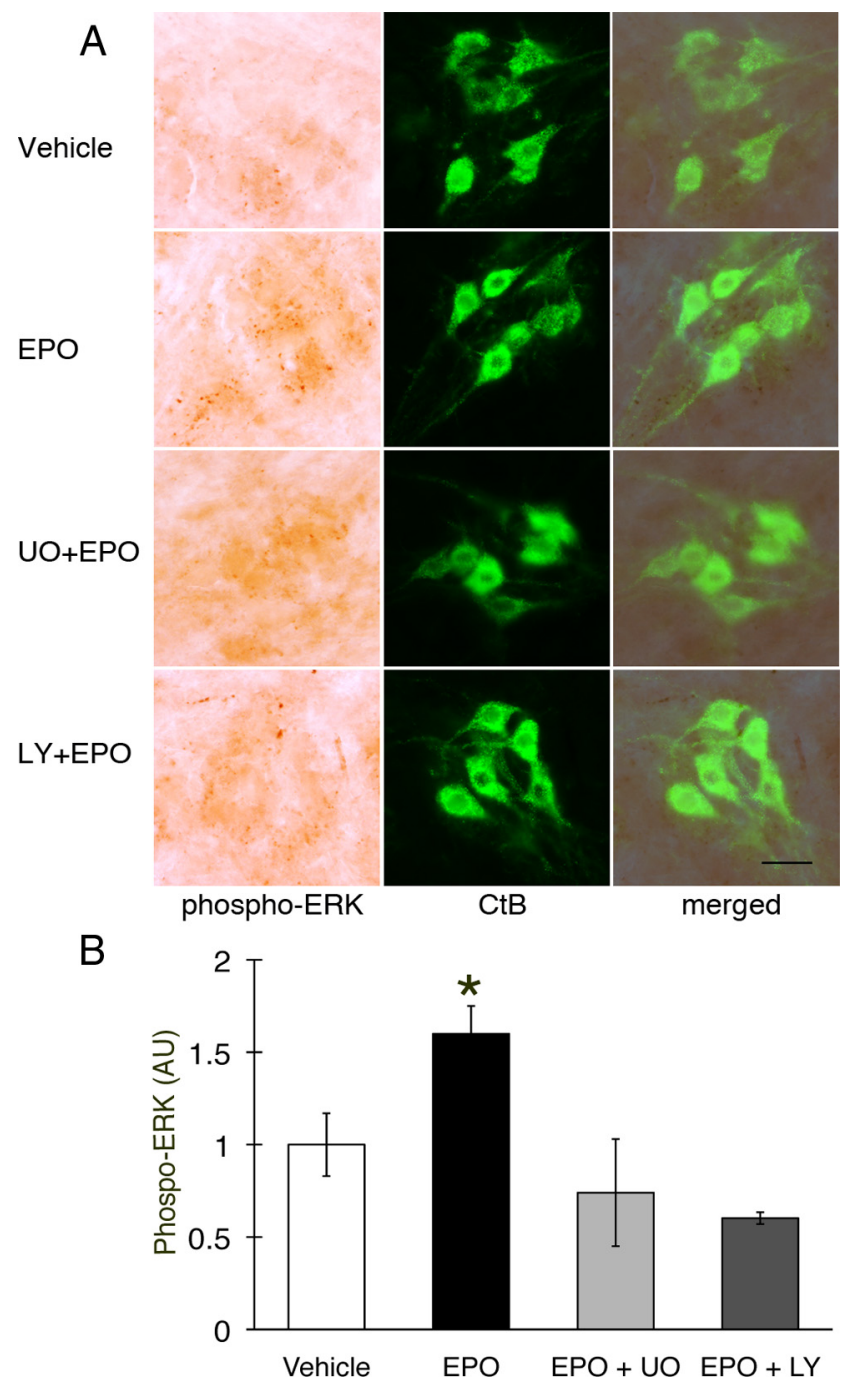

Figure 3. Phospho-ERK expression in ( 4 phrenic motor neurons after intrathecal EPO injection. $A$, Phospho-ERK (dark brown staining) is expressed in (4 phrenic motor neurons and is colocalized with CtB (top row, vehicle). pERK is upregulated after intrathecal EPO injection (middle row), and this upregulation is blocked by U0126 (U0; MEK/ERK inhibitor; second row from bottom) and the PI3K/Akt inhibitor LY294002 (LY; bottom row). B, Densitometry in CtBlabeled phrenic motor neurons showed increased phospho-ERK after intrathecal EPO- versus vehicle-treated rats. Pretreatment with U0126 and LY294002 brings pERK protein expression to vehicle levels. Data are means \pm 1 SEM. ${ }^{*} p<0.05$ versus all other groups. Scale bar, $100 \mu \mathrm{m}$.

U0126, an MEK inhibitor (dissolved in 100\% DMSO and diluted with aCSF to a final concentration of $100 \mathrm{~mm}$ in $20 \% \mathrm{DMSO}$; Promega) before EPO; (3) U0126 without EPO; (4) $12 \mu \mathrm{l}$ of LY294002, a PI3K inhibitor (dissolved in 100\% DMSO and diluted with aCSF to a final concentration of $100 \mathrm{~mm}$ in 20\% DMSO; Tocris Bioscience) before EPO; (5) LY294002 without EPO; or (6) or just $10 \mu$ l of vehicle ( $0.1 \% \mathrm{BSA}$ in aCSF). All drugs were slowly administered intrathecally over the course of $2 \mathrm{~min}$. When two drugs were used in the same protocol (e.g., U0126 + EPO), the inhibitor was given 15-20 min before EPO injections. When working with EPO, all syringes, vials, and catheters were incubated beforehand with vehicle to prevent protein binding. The optimal EPO dose used was chosen based on a preliminary dose-response curve.

\section{Results}

\section{Immunohistochemical experiments}

$E P O$ and EPO-R are expressed in identified phrenic motor neurons

DAB staining in C4 ventral horn (i.e., the region of the phrenic motor nucleus; Goshgarian and Rafols, 1981; Boulenguez et al.,

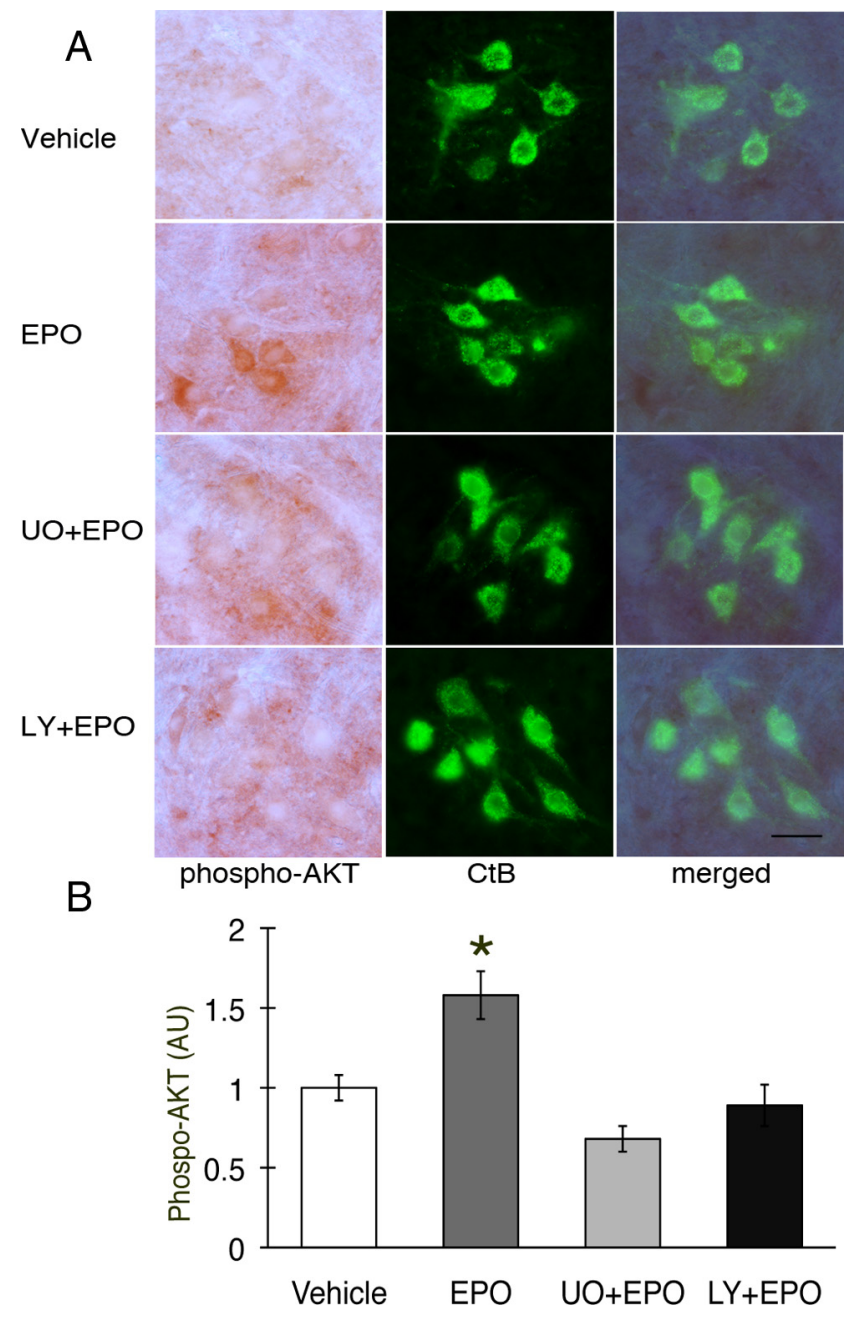

Figure 4. Phospho-Akt expression in C4 phrenic motor neurons after intrathecal EPO injection. $A$, Phospho-Akt (dark brown staining) is expressed in (4 phrenic motor neurons and is colocalized with CtB back-labeled phrenic motor neurons. pAkt is upregulated after EPO injection (middle rows), and that upregulation is blocked after LY294002 or U0126 pretreatment (bottom two rows). B, Densitometry in CtB-positive phrenic motor neurons showed increased phospho-Akt after intrathecal EPO- versus vehicle-treated rats $(p<0.05)$. pAkt is at contro levels after pretreatment with U0126 (U0) and after LY294002 (LY; $p<0.05$ ). Data are means \pm 1 SEM. ${ }^{*} p<0.05$ versus EPO alone; ${ }^{\#} p<0.05$ versus vehicle. Scale bar, $100 \mu \mathrm{m}$.

2007; Mantilla et al., 2009) revealed EPO immunolabeling in presumptive phrenic motor neurons (Fig. $1 A, B$ ). In rats that received $\mathrm{CtB}$ injections, $\mathrm{EPO}$ immunolabeling colocalized with $\mathrm{CtB}$ staining (i.e., within phrenic motor neurons; $n=5$ ). CtB-positive cells (Fig. $1 C-F$ ) are shown in coronal sections of $\mathrm{C} 4$ within the mediolateral ventral horn. EPO immunostaining is also found in smaller cells, possibly interneurons (Lane et al., 2008) or other non-identified somatic motor neurons.

EPO- $\mathrm{R}$ is also revealed via DAB staining in putative phrenic motor neurons (Fig. 2A,B) and, in rats receiving $\mathrm{CtB}$ injections, colocalizes with $\mathrm{CtB}$ immunoreactivity. Thus, both EPO and EPO-R are expressed in identified phrenic motor neurons (Fig. $2 C-F)$.

\section{EPO increases phospho-ERK and phospho-Akt in phrenic} motor neurons

Because EPO-R is expressed in phrenic motor neurons, and EPO-R signals via ERK MAP kinases and Akt, we hypothesized that intrathecal EPO injections at $\mathrm{C} 4$ would increase phosphorylation of ERK and Akt in the phrenic motor nucleus. We further 
Table 1. Body temperature (Tb), blood gases, $\mathrm{pH}$, mean arterial pressure (MAP), and standard base excess (SBE) in each treatment group

\begin{tabular}{|c|c|c|c|c|c|c|}
\hline Group & $\mathrm{Tb}\left({ }^{\circ} \mathrm{C}\right)$ & $\mathrm{PaO}_{2}(\mathrm{mmHg})$ & $\mathrm{PaCO}(\mathrm{mmHg})$ & pH & $\operatorname{MAP}(\mathrm{mmHg})$ & SBE \\
\hline \multicolumn{7}{|l|}{ Baseline } \\
\hline $\mathrm{aCSF}+0.1 \% \mathrm{BSA}$ & $37.2 \pm 0.2$ & $335.5 \pm 13.2$ & $46.0 \pm 0.9$ & $7.335 \pm 0.005$ & $121.3 \pm 5.9$ & $-1.15 \pm 0.41$ \\
\hline 20 IU EPO & $37.1 \pm 0.1$ & $305.9 \pm 13.7$ & $45.8 \pm 1.0$ & $7.347 \pm 0.009$ & $119.2 \pm 4.2$ & $-0.46 \pm 0.70$ \\
\hline U0126 alone & $37.4 \pm 0.1$ & $306.2 \pm 10.5$ & $46.4 \pm 0.9$ & $7.344 \pm 0.011$ & $117.3 \pm 7.3$ & $-0.52 \pm 0.69$ \\
\hline$L Y 294002+E P O$ & $37.1 \pm 0.2$ & $310.0 \pm 14.1$ & $47.5 \pm 0.4$ & $7.335 \pm 0.008$ & $116.8 \pm 4.6$ & $-0.46 \pm 0.57$ \\
\hline LY294002 alone & $37.7 \pm 0.1$ & $292.3 \pm 13.3$ & $46.1 \pm 0.8$ & $7.333 \pm 0.008$ & $110.7 \pm 7.1$ & $-1.36 \pm 0.61$ \\
\hline 20 IU EPO & $37.2 \pm 0.1$ & $297.4 \pm 14.8$ & $45.5 \pm 1.4$ & $7.344 \pm 0.010$ & $116.4 \pm 5.8$ & $-0.61 \pm 0.85$ \\
\hline $\mathrm{U} 0126+\mathrm{EPO}$ & $37.2 \pm 0.1$ & $319.3 \pm 18.0$ & $47.1 \pm 0.8$ & $7.334 \pm 0.016$ & $118.3 \pm 6.6$ & $-0.73 \pm 0.81$ \\
\hline U0126 alone & $37.2 \pm 0.2$ & $289.3 \pm 7.2$ & $47.2 \pm 0.7$ & $7.341 \pm 0.019$ & $112.0 \pm 15.8$ & $-0.10 \pm 1.05$ \\
\hline LY294002 + EPO & $37.2 \pm 0.2$ & $315.5 \pm 4.9$ & $48.0 \pm 0.3$ & $7.338 \pm 0.009$ & $108.6 \pm 2.0$ & $0.03 \pm 0.58$ \\
\hline LY294002 alone & $37.4 \pm 0.1$ & $300.0 \pm 8.6$ & $46.0 \pm 0.7$ & $7.336 \pm 0.008$ & $108.4 \pm 6.1$ & $-1.17 \pm 0.65$ \\
\hline \multicolumn{7}{|l|}{$30 \mathrm{~min}$} \\
\hline LY294002 + EPO & $37.3 \pm 0.1$ & $304.0 \pm 8.1$ & $48.0 \pm 0.7$ & $7.337 \pm 0.008$ & $107.6 \pm 2.5$ & $-0.10 \pm 0.58$ \\
\hline LY294002 alone & $37.3 \pm 0.1$ & $294.4 \pm 9.6$ & $46.3 \pm 0.8$ & $7.335 \pm 0.009$ & $102.2 \pm 5.5$ & $-1.04 \pm 0.64$ \\
\hline \multicolumn{7}{|l|}{$60 \mathrm{~min}$} \\
\hline $\mathrm{aCSF}+0.1 \% \mathrm{BSA}$ & $37.0 \pm 0.2$ & $324.8 \pm 8.5$ & $45.9 \pm 1.0$ & $7.340 \pm 0.010$ & $111.3 \pm 7.5$ & $-0.92 \pm 0.74$ \\
\hline 20 IU EPO & $37.2 \pm 0.1$ & $305.5 \pm 12.3$ & $45.8 \pm 1.0$ & $7.339 \pm 0.009$ & $109.2 \pm 6.6$ & $-1.01 \pm 0.71$ \\
\hline U0126 + EPO & $37.2 \pm 0.4$ & $331.5 \pm 1.8$ & $46.8 \pm 1.0$ & $7.360 \pm 0.001$ & $113.4 \pm 7.5$ & $0.95 \pm 0.39$ \\
\hline U0126 alone & $37.2 \pm 0.1$ & $300.7 \pm 6.8$ & $45.9 \pm 0.7$ & $7.343 \pm 0.017$ & $108.7 \pm 10.9$ & $-0.75 \pm 0.91$ \\
\hline LY294002 + EPO & $37.2 \pm 0.2$ & $302.6 \pm 6.3$ & $47.4 \pm 0.4$ & $7.337 \pm 0.007$ & $104.1 \pm 2.5$ & $-0.34 \pm 0.54$ \\
\hline LY294002 alone & $37.6 \pm 0.1$ & $299.6 \pm 10.9$ & $45.7 \pm 0.6$ & $7.343 \pm 0.010$ & $97.4 \pm 5.9$ & $-0.83 \pm 0.82$ \\
\hline \multicolumn{7}{|l|}{$90 \mathrm{~min}$} \\
\hline $\mathrm{aCSF}+0.1 \% \mathrm{BSA}$ & $37.1 \pm 0.2$ & $321.8 \pm 8.0$ & $45.7 \pm 1.0$ & $7.348 \pm 0.012^{*}$ & $108.2 \pm 6.8^{*}$ & $-0.52 \pm 0.79$ \\
\hline 20 IU EPO & $37.3 \pm 0.2$ & $305.9 \pm 11.4$ & $46.2 \pm 1.0$ & $7.337 \pm 0.011^{*}$ & $106.4 \pm 6.1^{*}$ & $-0.97 \pm 0.68$ \\
\hline
\end{tabular}

All values expressed as mean \pm SEM. * indicates significantly different from respective baseline measurement.

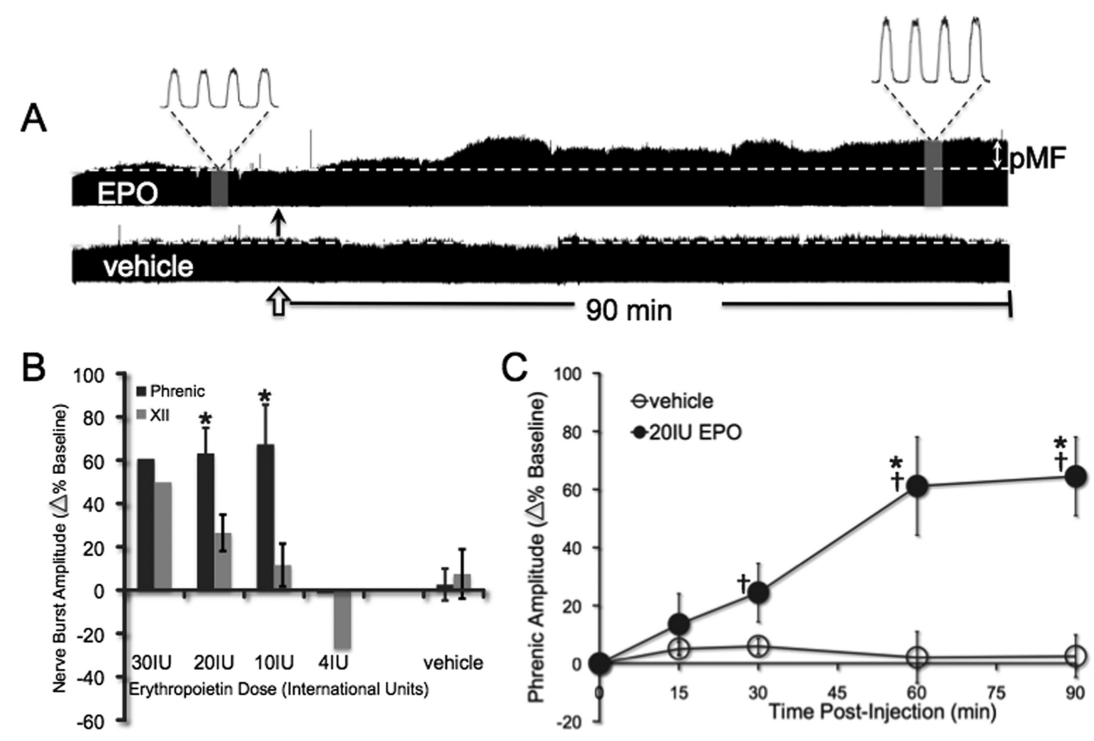

Figure 5. Intrathecal EPO elicits a long-lasting pMF. $\boldsymbol{A}$, Representative compressed phrenic neurograms showing either pMF after EPO injection (filled arrow) or no facilitation after vehicle injection (open arrow). $\boldsymbol{B}$, Preliminary dose-response curve for EPO; the dose subsequently used confers pMF without effects on hypoglossal (XII) activity. ${ }^{*} p<0.001$, significantly different from XII motor facilitation at same dose. $\boldsymbol{C}$, The amplitude of integrated phrenic bursts increases from baseline after $10 \mu \mathrm{l}$ (20 IU) EPO injections ( $n=8$; filled circles) and is significantly different from vehicle controls at the same time point (10 $\mu$; $n=6$; open circles). All values are change in phrenic burst amplitude as percentage baseline. Mean values $\pm 1 \mathrm{SEM} .{ }^{\dagger} p<0.05$, significantly different from baseline. ${ }^{*} p<0.05$, significantly different from vehicle at the same time. hypothesized that pretreatment with the MEK inhibitor U0126 or the PI3K inhibitor LY294002 would attenuate EPO-induced increases in pERK and pAkt, respectively.

Phospho-ERK staining was observed in putative $\mathrm{C} 4$ phrenic motor neurons of naive rats after vehicle injections (Fig. $3 A$ ) and in CtB back-labeled phrenic motor neurons (Fig. 3A, merged panels). Phospho-ERK labeling increased after EPO injections, but the increase was attenuated by pretreatment with U0126 (Fig. 3A). Densitometric analysis confirmed increased pERK expression after EPO treatment (Fig. 3B; $1.6 \pm 0.2$-fold vs vehicle; $p<0.05$ ), and U0126 pretreatment abolished this EPO-induced increase in pERK (0.7 \pm 0.3 -fold). Surprisingly, LY294002 pretreatment also attenuated the EPO-induced increase in pERK within phrenic motor neurons (Fig. 3B; $0.6 \pm$ 0.03-fold).

Phospho-Akt also colocalized with $\mathrm{CtB}$, confirming that this protein is expressed in phrenic motor neurons (Fig. $4 A)$. Intrathecal EPO increased Akt phosphorylation (Fig. 4A). Pretreatment with 
LY294002 decreased pAkt below control levels. Densitometric analysis showed that the increase in pAkt after EPO treatment was significant (Fig. $4 B ; 1.6 \pm 0.2$-fold vs vehicle; $p<0.05$ ). After pretreatment with LY294002, pAkt expression was attenuated (Fig. $4 B ; 0.7 \pm 0.1$-fold; $p<0.05$ ). Pretreatment with U0126 also brought pAkt levels below that of rats treated with EPO alone (Fig. $4 B ; 0.9 \pm 0.1 ; p<0.05$ ), indicating a complex interaction between these proteins.

Cervical EPO upregulates both pERK and pAkt within phrenic motor neurons. Pretreatment with the MEK/ERK inhibitor reversed increases in both pERK and pAkt, whereas pretreatment with a PI3K inhibitor decreased both pERK and pAkt levels. Thus, EPO activates ERK MAP kinases in phrenic motor neurons, although complex interactions between MEK/ERK and PI3K/Akt are observed after EPO-R activation.

\section{Electrophysiological experiments}

Regulation of physiological variables under anesthesia

Variables measured during electrophysiological recordings are shown in Table 1. There were no significant differences among experimental groups in body temperature, base excess, $\mathrm{PaO}_{2}$ (all measurements $>280 \mathrm{mmHg}$ ) or $\mathrm{PaCO}_{2}$ (all maintained within $1.5 \mathrm{mmHg}$ ). As noted in previous studies using this preparation (Baker-Herman and Mitchell, 2008), mean arterial pressure decreases throughout a protocol. However, there were no significant differences in this decrease between treatment groups. Blood $\mathrm{pH}$ tended to increase over time, and although the increase reaches statistical significance, (1) it is not different between groups, and (2) the difference is sufficiently small that its biological significance is doubtful (0.007 pH units).

\section{Cervical spinal EPO elicits dose-dependent pMF}

Representative traces of phrenic nerve activity before, during, and after EPO (10 $\mu \mathrm{l}, 20 \mathrm{IU})$ or vehicle injections into the C4 intrathecal space are shown in Figure $5 A$. A preliminary EPO dose-response curve is shown in Figure $5 B$. The dose used in subsequent studies is the dose that affected phrenic motor output without inducing apparent hypoglossal motor facilitation, which would suggest spread to brainstem sites. Mean responses to this dose (20 IU) are shown in Figure 5C. Phrenic burst amplitude was significantly increased from baseline by $30 \mathrm{~min}$ and at all time points thereafter (all $p<0.001 ; n=8$ ), indicating pMF. Vehicle control rats did not exhibit significant changes in phrenic burst amplitude at any time (all $p>0.05 ; n=6)$. Changes in phrenic burst amplitude after EPO injections were significantly greater than in vehicle-treated rats after $60 \mathrm{~min}$ (all $p<0.001$ ). Changes in hypoglossal (XII) motor output were apparent only at higher doses of EPO (Fig. 5B).

\section{EPO-induced pMF requires spinal ERK activation}

To test the hypothesis that EPO-induced pMF requires spinal ERK activation, rats were pretreated with the potent, cellpermeable MEK inhibitor U0126 before EPO administration. Pretreatment with U0126 abolished EPO-induced pMF for at least $90 \min$ ( $16 \pm 11 \%$ baseline; $n=5 ; p>0.05$ vs baseline; Fig. $6 A)$. pMF was significantly greater in rats treated with EPO alone at time points $>60 \mathrm{~min}$ after injection (all $p<0.008$ ). U0126 alone had no effect on phrenic motor output at any time (all $p>$ $0.05)$. The U0126 dose was chosen based on a previous study from our laboratory (Dale-Nagle et al., 2011).

EPO-induced pMF requires spinal Akt activation

To test the hypothesis that EPO-induced pMF requires spinal Akt activation, rats were pretreated with the PI3K inhibitor LY294002
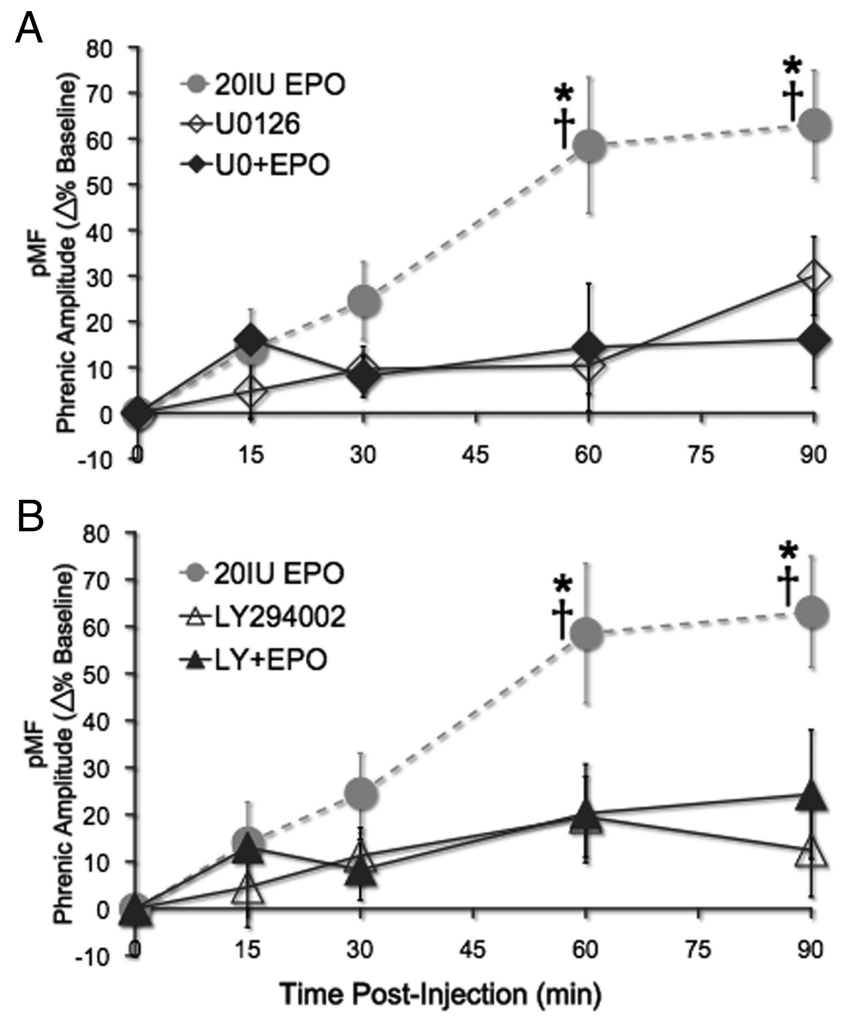

Figure 6. EPO-induced $\mathrm{pMF}$ is dependent on spinal ERK and Akt activation. $\boldsymbol{A}$, Spinal EPO elicits pMF (gray dashed line; ${ }^{*} p<0.001$, significant difference from U0126 + EPO and U0126 alone; $n=8$ ). Pretreatment with the MEK inhibitor U0126 abolishes EPO-induced pMF; phrenic amplitude does not increase after baseline measurement (filled diamonds; $n=5 ;$ all $p>0.05$ ). U0126 alone had no significant effect on phrenic motor output (open diamonds; $n=6$; all $p>$ 0.05 ), and there was no significant difference between $\mathrm{U} 0126+\mathrm{EPO}$ and U0126 alone (all $p>$ 0.05). $\boldsymbol{B}$, Gray dashed line shows EPO-induced pMF (* indicates significant difference from both LY294002 + EP0 and LY294002 alone). After treatment with the PI3K inhibitor LY294002, EPO-induced pMF is abolished (filled triangles; $n=5$; all $p>0.05$ ). LY294002 alone had no significant effect on phrenic motor output (open triangles; $n=7$; all $p>0.05$ ), and there was no significant difference between LY294002 + EPO and LY294002 alone (all $p>0.05$ ). All values are expressed as change in phrenic burst amplitude expressed as percentage baseline. Mean values \pm 1 SEM. ${ }^{\dagger} p<0.001$, significantly different from baseline; ${ }^{*} p<0.001$, significantly different from vehicle at the same time point.

$20 \mathrm{~min}$ before EPO administration. Figure $6 B$ illustrates that LY294002 pretreatment abolished EPO-induced pMF at the 60 min time point; there was no significant pMF 90 min after EPO injection ( $24 \pm 14 \%$ baseline; $n=5 ; p>0.05$ vs baseline). LY294002 alone had no effect on phrenic burst amplitude compared with baseline values or vehicle controls (12 $\pm 10 \% ; n=7$; $p>0.05)$. LY294002 doses were chosen based on previous studies (Dale-Nagle et al., 2011).

Spinal EPO elicits minimal phrenic burst frequency facilitation Rats treated with 10 IU of EPO showed a slight but significant increase in respiratory burst frequency starting $60 \mathrm{~min}$ after injection versus vehicle controls (Fig. $7 A$; all $p<0.027 ; n=3$ ) and at all time points thereafter versus baseline (all $p<0.027)$. However, neither higher (e.g., $30 \mathrm{IU}, n=2$ and $20 \mathrm{IU}, n=8$ ) nor lower (e.g., $4 \mathrm{IU}, n=2$ ) doses of EPO elicited similar frequency facilitation (vs baseline or vehicle controls for at least $90 \mathrm{~min}$ after EPO; all $p>0.05$; Fig. $7 B$ ). Figure $7, C$ and $D$, illustrates that there were no significant differences (vs baseline or controls) in frequency for rats treated with $\mathrm{U} 0126+\mathrm{EPO}(n=5 ; p>0.05)$, U0126 alone $(n=6 ; p>0.05), \mathrm{LY} 294002+\operatorname{EPO}(n=5 ; p>$ $0.05)$, or LY294002 alone $(n=7 ; p>0.05)$. Thus, EPO-induced 

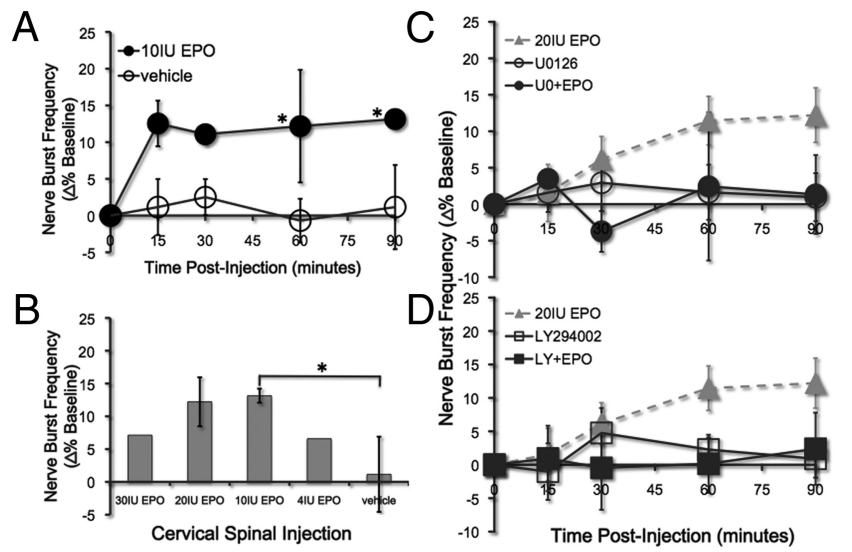

Figure 7. Effects of drug administration on nerve burst frequency. $\boldsymbol{A}$, Intrathecal administration of 10 IU EPO (filled circles) elicits a small facilitation in nerve burst frequency at $60 \mathrm{~min}$ after injection versus baseline and vehicle controls (open circles; $n=4$; ${ }^{*} p<0.027$ ). $\boldsymbol{B}$, The only dose of EPO that elicited frequency facilitation was $10 \mathrm{IU}\left({ }^{*} p<0.027\right)$. Higher ( 20 and 30 $\mathrm{IU}$ ) and lower (4 IU) doses did not elicit frequency facilitation (all $p>0.05$ ). C, D, No other treatments, including U0126, U0126 + EPO, LY294002, and LY294002 + EPO, elicited frequency facilitation versus baseline (all $p>0.05$ ). All values are expressed as change in nerve burst frequency (percentage baseline). Mean values $\pm 1 \mathrm{SEM}$.

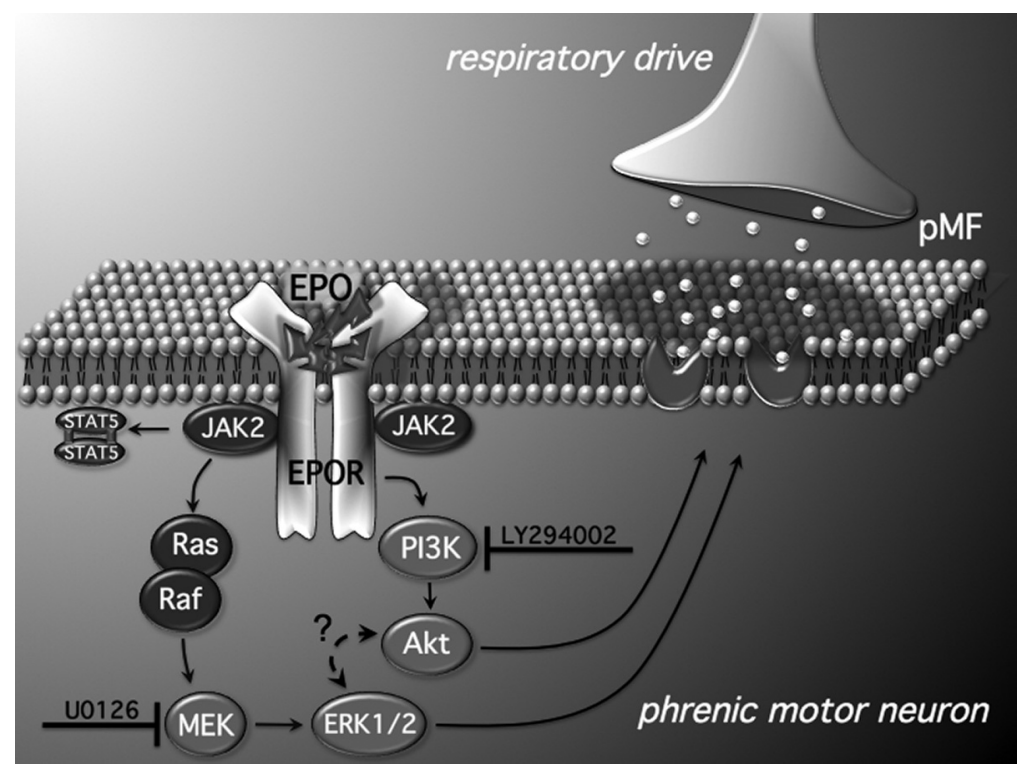

Figure 8. Working model of EPO-induced $\mathrm{PMF}$. EPO binds EPO-R, in either an autocrine or paracrine manner, initiating the JAK2/STAT5, MEK/ERK, and PI3K/Akt pathways. Both the MEK/ERK and PI3K/Akt pathways are required for EPO-induced pMF because the MEK inhibitor (U0126) and the PI3K inhibitor (LY294002) abolish EP0-induced pMF. However, because pretreatment with LY294002 inhibits pERK expression in phrenic motor neurons, there may be complex interactions between these pathways that are unique to the EPO signaling cascade (Schmidt et al., 2004). Although mechanisms downstream from ERK and Akt are unknown, EPO may increase glutamate receptor insertion on the postsynaptic membrane between premotor and phrenic motor neurons, thereby amplifying synaptic inputs and eliciting pMF.

frequency facilitation is small ( $\sim 13 \%$ above baseline) and variable (only observed at one mid-range EPO dose).

\section{Discussion}

EPO, originally described as a hematopoietic factor (Bert, 1882; Bert, 1878; Jourdanet, 1875), was recently discovered in the CNS (Masuda et al., 1994; Digicaylioglu et al., 1995; Marti et al., 1996; Morishita et al., 1997; Bernaudin et al., 1999; Brines et al., 2000) in which it exerts neurotrophic and neuroprotective effects on neurons, including motor neurons (Celik et al., 2002; Iwasaki et al., 2002; Mennini et al., 2006; Koh et al., 2007; Nagańska et al.,
2010). EPO plays an important role in hippocampal synaptic plasticity (Weber et al., 2002; Adamcio et al., 2008) and modulates breathing via peripheral and central neural mechanisms (Soliz et al., 2005, 2007). Here we demonstrate that EPO is involved in spinal respiratory motor plasticity. Specifically, cervical spinal EPO-R activation elicits long-lasting pMF. In association, EPO-R activation increases phosphorylated ERK and Akt expression within identified phrenic motor neurons. EPO-R-induced pMF appears to require both MEK/ERK and PI3K/Akt activity, consistent with reported EPO signaling cascades (Gobert et al., 1995; Bao et al., 1999). EPO-induced pMF and increased phospho-ERK expression are both blocked by MEK and PI3K inhibition. In addition, MEK and the PI3K inhibition also blocked EPO-induced Akt phosphorylation within phrenic motor neurons. Although immunohistochemistry reveals that both EPO and its primary receptor are located on phrenic motor neurons, suggesting that possible autocrine actions and the possibility of paracrine actions should also be considered. Our working model of EPO-induced pMF is shown in Figure 8.

Because EPO expression is increased during hypoxia via HIF$1 \alpha$ - or HIF- $2 \alpha$-dependent transcriptional regulation (Wang and Semenza, 1995; Wang et al., 1995; Yeo et al., 2008), EPO may be involved in well-known models of respiratory motor plasticity elicited by prolonged or repetitive hypoxia (Powell et al., 1998; Mitchell and Johnson, 2003; Mahamed and Mitchell, 2007).

\section{ERK and EPO-induced pMF}

ERK1/2 are involved in hippocampal synaptic plasticity (Impey et al., 1999; Valjent et al., 2001; Sweatt, 2004), long-term spatial memory formation (Brambilla et al., 1997; Kornhauser and Greenberg, 1997; Blum et al., 1999; Selcher et al., 1999), facilitation of the Aplysia gill withdrawal reflex (Martin et al., 1997), and respiratory motor plasticity.

Multiple cellular cascades lead to pMF and frequently converge on ERK and/or Akt signaling (Dale-Nagle et al., 2010a). One well-known form of pMF is pLTF after acute intermittent hypoxia (Fuller et al., 2000; Mitchell et al., 2001). New BDNF synthesis is necessary and sufficient for pLTF, followed by activation of the high-affinity BDNF receptor TrkB (BakerHerman et al., 2004). TrkB subsequently increases ERK phosphorylation near the phrenic motor nucleus (Wilkerson and Mitchell, 2009), and MEK/ERK signaling is necessary for pLTF (Hoffman and Mitchell, unpublished observations). VEGF-induced pMF is also MEK/ERK dependent, at least in part (Dale-Nagle et al., 2011). Collectively, available data indicate an important role for ERK in spinal respiratory motor plasticity, including EPO-induced pMF.

\section{Akt- and EPO-induced pMF}

The PI3K/Akt pathway is also involved in synaptic plasticity (Franke et al., 1997), including chemotaxis learning in Caenorhabditis elegans (Tomioka et al., 2006), hippocampal LTP (Opazo et al., 2003), and fear conditioning in rat prefrontal cor- 
tex (Sui et al., 2008). Here we show that the PI3K/Akt pathway is crucial for EPO-induced pMF.

Akt phosphorylation and/or activation is important in some forms of pMF that involve $\mathrm{G}_{\mathrm{s}}$-protein-coupled metabotropic receptors (Dale-Nagle et al., 2010a). Increased Akt phosphorylation is associated with pMF induced by spinal activation of adenosine $2 \mathrm{a}$ or serotonin type 7 receptors, a novel pathway eliciting TrkB trans-activation without new BDNF synthesis (Golder et al., 2008; Hoffman and Mitchell, 2011). Although the requirement for PI3K/Akt signaling has not been tested for A2a receptorinduced $\mathrm{pMF}$, it is necessary for $5-\mathrm{HT}_{7}$-receptor-induced $\mathrm{pMF}$ (Hoffman and Mitchell, 2011). Spinal VEGF receptor activation also elicits pMF via an Akt-dependent mechanism (Dale-Nagle et al., 2011). Thus, Akt signaling is critical for multiple forms of spinal respiratory motor plasticity, including EPO-induced pMF.

\section{ERK/Akt interactions}

Our interpretations concerning the respective roles of MEK/ERK and PI3K/Akt signaling in EPO-induced pMF were complicated by effects of LY294002 on phospho-ERK levels in phrenic motor neurons, as well as effects of U0126 on phospho-Akt levels (Fig. $3 B$ ). Although one possibility is that the drugs have nonspecific effects, a detailed study of direct LY294002 interactions with various proteins (including PI3K family members) revealed no interactions between LY294002 and MEK or ERK MAP kinases (Gharbi et al., 2007). Conversely, some indirect MEK/ERK and PI3K/Akt interactions have been reported (Ballif and Blenis, 2001; Hayashi et al., 2008; Kodiha et al., 2009). Of particular note, EPO-R signaling is more complex than previously thought; Schmidt et al. (2004) report that PI3K activity is necessary for EPO-induced MEK/ERK activation depending on the EPO concentration and interactions with other growth factors. Thus, we cannot be sure whether Akt is directly or indirectly necessary for EPO-induced pMF because it is required to activate ERK. Regardless, our fundamental conclusions remain sound: both ERK and Akt activation are necessary for full expression of EPOinduced $\mathrm{pMF}$.

\section{EPO-induced frequency facilitation}

In anesthetized, paralyzed, vagotomized and ventilated rats, pMF is most prominent in phrenic burst amplitude, with small, inconsistent effects on respiratory burst frequency (Baker-Herman and Mitchell, 2008). In the present study, we performed a limited cervical EPO dose-response curve, enabling us to prevent drug spread to the brain and to localize drug effects to spinal segments associated with the phrenic motor nucleus. As a marker for brain effects, we monitored XII nerve activity, which did not show significant changes in burst amplitude after 10 IU EPO injections. However, this same intrathecal dose elicited a small increase in burst frequency that began $60 \mathrm{~min}$ after injection. This frequency facilitation could be attributable to undetected spread of EPO to brainstem regions; however, larger EPO doses (20 and $30 \mathrm{IU}$, which should have increased rostral spread) did not elicit similar frequency responses. Thus, we suspect that the frequency facilitation at 10 IU arose from (1) spinal EPO-R activation in ascending sensory pathways that converge on brainstem rhythm generating neurons and/or (2) a spontaneous, low baseline frequency before EPO administration in the $10 \mathrm{IU}$ group (not the 20 or 30 IU groups; data not shown). Although there is no explanation for this relatively low baseline frequency in the 10 IU EPO group, frequency facilitation after acute intermittent hypoxia is negatively correlated with baseline frequency (Baker-Herman and Mitchell, 2008). Thus, we consider the frequency facilitation observed here to be a spurious result. Because of the small and inconsistent nature of this frequency facilitation, we did not explore it further.

\section{Possible significance}

We do not suspect that EPO plays a role in pLTF after acute intermittent hypoxia, a distinct form of pMF that requires new BDNF synthesis via translation of existing mRNA (BakerHerman et al., 2004). The time domain of pLTF is too short for transcriptional regulation of EPO $(<1 \mathrm{~h})$.

After exposure to intermittent hypoxia for days (or longer), pLTF is enhanced, demonstrating a form of respiratory metaplasticity (Ling et al., 2001; Wilkerson and Mitchell, 2009). EPO has considerable potential to play a role in respiratory metaplasticity after repetitive or prolonged exposures to intermittent (or sustained) hypoxia, such as ventilatory acclimatization to chronic hypoxia (Powell et al., 1998). As yet, these ideas remain untested.

\section{Possible therapeutic implications}

We recently attempted to harness respiratory plasticity induced by repetitive acute intermittent hypoxia as a therapeutic approach in cases of ventilatory compromise (Mitchell, 2007), such as after cervical spinal cord injury (Vinit and Kastner, 2009; Vinit et al., 2009; Dale-Nagle et al., 2010b; Trumbower et al., 2012) or amyotrophic lateral sclerosis (ALS) (N. N. Nichols and G. S. Mitchell, unpublished observations).

EPO expression is upregulated after spinal injury and can prevent apoptosis from anoxia, excitotoxicity, and glucose deprivation (Brines and Cerami, 2006). However, because of the longer time frames for CNS EPO production, endogenous upregulation of this molecule is unlikely to play any major role in acute phases of injury. Consequently, recent studies have used exogenous EPO application to promote neuroprotection and functional recovery after spinal injury (Gorio et al., 2002; Kaptanoglu et al., 2004; Boran et al., 2005; Arishima et al., 2006; Cetin et al., 2006; Grasso et al., 2006; Okutan et al., 2007; Vitellaro-Zuccarello et al., 2007, 2008; Fumagalli et al., 2008; Zhang et al., 2010). An unintended outcome of this EPO administration may well have been increased breathing, which can be good or bad depending on the prevailing state of the patient. If breathing is inadequate as a result of cervical injury, then EPO-induced pMF is expected to restore lost breathing function.

EPO has also been investigated for its potential as an ALS treatment, including studies on spinal cultures (Nagańska et al., 2010), SOD1 ${ }^{\text {G93A }}$ mice (Grignaschi et al., 2007; Koh et al., 2007), and human patients (Maurer et al., 2008; Lauria et al., 2009). Early results suggest a degree of neuroprotection, although benefits have been limited and such treatments are unlikely to "cure" the disease.

We suggest that an unrecognized benefit of EPO treatments may be improved respiratory (and somatic) motor function attributable to mechanisms of induced motor plasticity. These effects could be of crucial importance because ventilatory complications are the leading cause of death after spinal injury or in ALS patients.

\section{References}

Adamcio B, Sargin D, Stradomska A, Medrihan L, Gertler C, Theis F, Zhang M, Müller M, Hassouna I, Hannke K, Sperling S, Radyushkin K, El-Kordi A, Schulze L, Ronnenberg A, Wolf F, Brose N, Rhee JS, Zhang W, Ehrenreich H (2008) Erythropoietin enhances hippocampal long-term potentiation and memory. BMC Biol 6:37.

Anderson J, Sandhir R, Hamilton ES, Berman NE (2009) Impaired expres- 
sion of neuroprotective molecules in the HIF-1alpha pathway following traumatic brain injury in aged mice. J Neurotrauma 26:1557-1566.

Arishima Y, Setoguchi T, Yamaura I, Yone K, Komiya S (2006) Preventive effect of erythropoietin on spinal cord cell apoptosis following acute traumatic injury in rats. Spine 31:2432-2438.

Bach KB, Mitchell GS (1996) Hypoxia-induced long-term facilitation of respiratory activity is serotonin dependent. Respir Physiol 104:251-260.

Baker-Herman TL, Mitchell GS (2008) Determinants of frequency longterm facilitation following acute intermittent hypoxia in vagotomized rats. Respir Physiol Neurobiol 162:8-17.

Baker-Herman TL, Fuller DD, Bavis RW, Zabka AG, Golder FJ, Doperalski NJ, Johnson RA, Watters JJ, Mitchell GS (2004) BDNF is necessary and sufficient for spinal respiratory plasticity following intermittent hypoxia. Nat Neurosci 7:48-55.

Ballif BA, Blenis J (2001) Molecular mechanisms mediating mammalian mitogen activated protein kinase (MAPK) kinase (MEK)-MAPK cell survival signals. Cell Growth Differ 12:397-408.

Bao H, Jacobs-Helber SM, Lawson AE, Penta K, Wickrema A, Sawyer ST (1999) Protein kinase B (c-Akt), phosphatidylinositol 3-kinase, and STAT5 are activated by erythropoietin (EPO) in HCD57 erythroid cells but are constitutively active in an EPO-independent, apoptosis-resistant subclone (HCD57-SREI cells). Blood 93:3757-3773.

Bernaudin M, Marti HH, Roussel S, Divoux D, Nouvelot A, MacKenzie ET, Petit E (1999) A potential role for erythropoietin in focal permanent cerebral ischemia in mice. J Cereb Blood Flow Metab 19:643-651.

Bert P (1878) La pression barométrique: recherches de physiologie expérimentale. Paris: Masson.

Bert P (1882) Sur la richesse en hemoglobine du sang des animaux vivant sur les hauts lieux. CR Acad Sci Paris 94:805-807.

Blum S, Moore AN, Adams F, Dash PK (1999) A mitogen-activated protein kinase cascade in the CA1/CA2 subfield of the dorsal hippocampus is essential for long-term spatial memory. J Neurosci 19:3535-3544.

Boran BO, Colak A, Kutlay M (2005) Erythropoietin enhances neurological recovery after experimental spinal cord injury. Restor Neurol Neurosci 23:341-345.

Boulenguez P, Gestreau C, Vinit S, Stamegna JC, Kastner A, Gauthier P (2007) Specific and artefactual labeling in the rat spinal cord and medulla after injection of monosynaptic retrograde tracers into the diaphragm. Neurosci Lett 417:206-211.

Brambilla R, Gnesutta N, Minichiello L, White G, Roylance AJ, Herron CE, Ramsey M, Wolfer DP, Cestari V, Rossi-Arnaud C, Grant SG, Chapman PF, Lipp HP, Sturani E, Klein R (1997) A role for the Ras signalling pathway in synaptic transmission and long-term memory. Nature 390:281-286.

Brines M, Cerami A (2006) Discovering erythropoietin's extra-hematopoietic functions: biology and clinical promise. Kidney Int 70:246-250.

Brines ML, Ghezzi P, Keenan S, Agnello D, de Lanerolle NC, Cerami C, Itri LM, Cerami A (2000) Erythropoietin crosses the blood brain barrier to protect against experimental brain injury. Proc Natl Acad Sci U S A 97:10526-10531.

Celik M, Gökmen N, Erbayraktar S, Akhisaroglu M, Konakc S, Ulukus C, Genc S, Genc K, Sagiroglu E, Cerami A, Brines M (2002) Erythropoietin prevents motor neuron apoptosis and neurologic disability in experimental spinal cord ischemic injury. Proc Natl Acad Sci U S A 99:2258-2263.

Cetin A, Nas K, Büyükbayram H, Ceviz A, Olmez G (2006) The effects of systemically administered methylprednisolone and recombinant human erythropoietin after acute spinal cord compressive injury in rats. Eur Spine J 15:1539-1544.

Connolly DT, Heuvelman DM, Nelson R, Olander JV, Eppley BL, Delfino JJ, Siegel NR, Leimgruber RM, Feder J (1989) Tumor vascular permeability factor stimulates endothelial cell growth and angiogenesis. J Clin Invest 84:1470-1478.

Dale-Nagle EA, Hoffman MS, MacFarlane PM, Mitchell GS (2010a) Multiple pathways to long-lasting phrenic motor facilitation. Adv Exp Med Biol 669:225-230.

Dale-Nagle EA, Hoffman MS, MacFarlane PM, Satriotomo I, Lovett-Barr MR, Vinit S, Mitchell GS (2010b) Spinal plasticity following intermittent hypoxia: implications for spinal injury. Ann N Y Acad Sci 1198:252-259.

Dale-Nagle EA, Satriotomo I, Mitchell GS (2011) Spinal vascular endothelial growth factor elicits phrenic motor facilitation via ERK and Akt signaling. J Neurosci 31:7682-7690.
Damen JE, Mui AL, Puil L, Pawson T, Krystal G (1993) Phosphatidylinositol 3 kinase associates, via its Src homology 2 domains, with the activated erythropoietin receptor. Blood 81:3204-3210.

Digicaylioglu M, Bichet S, Marti HH, Wenger RH, Rivas LA, Bauer C, Gassmann M (1995) Localization of specific erythropoietin binding sites in defined areas of the mouse brain. Proc Natl Acad Sci U S A 92:3717-3720.

Forsythe JA, Jiang BH, Iyer NV, Agani F, Leung SW, Koos RD, Semenza GL (1996) Activation of vascular endothelial growth factor gene transcription by hypoxia-inducible factor 1 . Mol Cell Biol 16:4604-4613.

Franke TF, Kaplan DR, Cantley LC (1997) PI3K: downstream AKTion blocks apoptosis. Cell 88:435-437.

Fuller DD, Bach KB, Baker TL, Kinkead R, Mitchell GS (2000) Long term facilitation of phrenic motor output. Respir Physiol 121:135-146.

Fumagalli F, Madaschi L, Brenna P, Caffino L, Marfia G, Di Giulio AM, Racagni G, Gorio A (2008) Single exposure to eythropoietin modulates nerve growth factor expression in the spinal cord following traumatic injury: comparison with methylprednisolone. Eur J Pharmacol 578:19-27.

Gassmann M, Soliz J (2009) Erythropoietin modulates the neural control of hypoxic ventilation. Cell Mol Life Sci 66:3575-3582.

Gassmann M, Tissot van Patot M, Soliz J (2009) The neuronal control of hypoxic ventilation: erythropoietin and sexual dimorphism. Ann NY Acad Sci 1177:151-161.

Gharbi SI, Zvelebil MJ, Shuttleworth SJ, Hancox T, Saghir N, Timms JF, Waterfield MD (2007) Exploring the specificity of the PI3K family inhibitor LY294002. Biochem J 404:15-21.

Gobert S, Duprez V, Lacombe C, Gisselbrecht S, Mayeux P (1995) The signal transduction pathway of erythropoietin involves three forms of mitogen activated protein (MAP) kinases in UT7 erythroleukemia cells. Eur J Biochem 234:75-83.

Golder FJ (2008) Receptor tyrosine kinases and respiratory motor plasticity. Respir Physiol Neurobiol 164:242-251.

Golder FJ, Ranganathan L, Satriotomo I, Hoffman M, Lovett-Barr MR, Watters JJ, Baker-Herman TL, Mitchell GS (2008) Spinal adenosine A2a receptor activation elicits long-lasting phrenic motor facilitation. J Neurosci 28:2033-2042.

Gorio A, Gokmen N, Erbayraktar S, Yilmaz O, Madaschi L, Cichetti C, Di Giulio AM, Vardar E, Cerami A, Brines M (2002) Recombinant human erythropoietin counteracts secondary injury and markedly enhances neurological recovery from experimental spinal cord trauma. Proc Natl Acad Sci U S A 99:9450-9455.

Goshgarian HG, Rafols JA (1981) The phrenic nucleus of the albino rat: a correlative HRP and Golgi study. J Comp Neurol 201:441-456.

Grasso G, Sfacteria A, Erbayraktar S, Passalacqua M, Meli F, Gokmen N, Yilmaz O, La Torre D, Buemi M, Iacopino DG, Coleman T, Cerami A, Brines M, Tomasello F (2006) Amelioration of spinal cord compressive injury by pharmacological preconditioning with erythropoietin and a nonerythropoietic erythropoietin derivative. J Neurosurg Spine $4: 310-318$

Grignaschi G, Zennaro E, Tortarolo M, Calvaresi N, Bendotti C (2007) Erythropoietin does not preserve motor neurons in a mouse model of familial ALS. Amyotroph Lateral Scler 8:31-35.

Hayashi H, Tsuchiya Y, Nakayama K, Satoh T, Nishida E (2008) Down regulation of the PI3-kinase/Akt pathway by ERK MAP kinase in growth factor signaling. Genes Cells 13:941-947.

He TC, Zhuang H, Jiang N, Waterfield MD, Wojchowski DM (1993) Association of the p85 regulatory subunit of phosphatidylinositol 3-kinase with an essential erythropoietin receptor subdomain. Blood 82:3530-3538

Hoffman MS, Mitchell GS (2011) Spinal 5-HT receptor activation induces long-lasting phrenic motor facilitation. J Physiol 589:1397-1407.

Impey S, Obrietan K, Storm DR (1999) Making new connections: role of ERK/MAP kinase signaling in neuronal plasticity. Neuron 23:11-14.

Iwasaki Y, Ikeda K, Ichikawa Y, Igarashi O, Iwamoto K, Kinoshita M (2002) Protective effect of interleukin-3 and erythropoietin on motor neuron death after neonatal axotomy. Neurol Res 24:643-646.

Jourdanet D (1875) Influence de la pression de l'air sur la vie de l'homme. Paris: Masson.

Juul SE (2000) Nonerythropoietic roles of erythropoietin in the fetus and neonate. Clin Perinatol 27:527-541.

Kaptanoglu E, Solaroglu I, Okutan O, Surucu HS, Akbiyik F, Beskonakli E 
(2004) Erythropoietin exerts neuroprotection after acute spinal cord injury in rats: effect on lipid peroxidation and early ultrastructural findings. Neurosurg Rev 27:113-120.

Kilic E, Kilic U, Soliz J, Bassetti CL, Gassmann M, Hermann DM (2005) Brain derived erythropoietin protects from focal cerebral ischemia by dual activation of ERK-1/-2 and Akt pathways. FASEB J 19:2026-2028.

Kodiha M, Bański P, Stochaj U (2009) Interplay between MEK and PI3 kinase signaling regulates the subcellular localization of protein kinases ERK1/2 and Akt upon oxidative stress. FEBS Lett 583:1987-1993.

Koh SH, Kim Y, Kim HY, Cho GW, Kim KS, Kim SH (2007) Recombinant human erythropoietin suppresses symptom onset and progression of G93A-SOD1 mouse model of ALS by preventing motor neuron death and inflammation. Eur J Neurosci 25:1923-1930.

Kornhauser JM, Greenberg ME (1997) A kinase to remember: dual roles for MAP kinase in long-term memory. Neuron 18:839-842.

Lane MA, White TE, Coutts MA, Jones AL, Sandhu MS, Bloom DC, Bolser DC, Yates BJ, Fuller DD, Reier PJ (2008) Cervical prephrenic interneurons in the normal and lesioned spinal cord of the adult rat. J Comp Neurol 511:692-709.

Lauria G, Campanella A, Filippini G, Martini A, Penza P, Maggi L, Antozzi C, Ciano C, Beretta P, Caldiroli D, Ghelma F, Ferrara G, Ghezzi P, Mantegazza R (2009) Erythropoietin in amyotrophic lateral sclerosis: a pilot, randomized, double-blind, placebo-controlled study of safety and tolerability. Amyotroph Lateral Scler 10:410-415.

Ling L, Fuller DD, Bach KB, Kinkead R, Olson EB Jr, Mitchell GS (2001) Chronic intermittent hypoxia elicits serotonin-dependent plasticity in the central neural control of breathing. J Neurosci 21:5381-5388.

Liu Y, Cox SR, Morita T, Kourembanas S (1995) Hypoxia regulates vascular endothelial factor gene expression in endothelial cells. Indentification of a $5^{\prime}$ enhancer. Circ Res 77:638-643.

Mahamed S, Mitchell GS (2007) Is there a link between intermittent hypoxia induced respiratory plasticity and obstructive sleep apnoea? Exp Physiol 92:27-37.

Mantilla CB, Zhan WZ, Sieck GC (2009) Retrograde labeling of phrenic motoneurons by intrapleural injection. J Neurosci Methods 182:244-249.

Marti HH, Wenger RH, Rivas LA, Straumann U, Digicaylioglu M, Henn V, Yonekawa Y, Bauer C, Gassmann M (1996) Erythropoietin gene expression in human, monkey and murine brain. Eur J Neurosci 8:666-676.

Martin KC, Michael D, Rose JC, Barad M, Casadio A, Zhu H, Kandel ER (1997) MAP kinase translocates into the nucleus of the presynaptic cell and is required for long-term facilitation in Aplysia. Neuron 18:899-912.

Masuda S, Okano M, Yamagishi K, Nagao M, Ueda M, Sasaki R (1994) A novel site oferythropoietin production. Oxygen-dependent production in cultured rat astrocytes. J Biol Chem 269:19488-19493.

Maurer MH, Schäbitz WR, Schneider A (2008) Old friends in new constellations - the hematopoietic growth factors G-CSF, GM-CSF and EPO for the treatment of neurological diseases. Curr Med Chem 15:1407-1411.

Mayeux P, Dusanter-Fourt I, Muller O, Mauduit P, Sabbah M, Druker B, Vainchenker W, Fischer S, Lacombe C, Gisselbrecht S (1993) Erythropoietin induces the association of phosphatidylinositol $3^{\prime}$ kinase with a tyrosine phosphorylated complex containing the erythropoietin receptor. Eur J Biochem 216:821-828.

Mazur M, Miller RH, Robinson S (2010) Postnatal erythropoietin treatment mitigates neural cell loss after systemic prenatal hypoxic-ischemic injury. J Neurosurg Pediatr 6:206-221.

Mennini T, De Paola M, Bigini P, Mastrotto C, Fumagalli E, Barbera S, Mengozzi M, Viviani B, Corsini E, Marinovich M, Torup L, Van Beek J, Leist M, Brines M, Cerami A, Ghezzi P (2006) Nonhematopoietic erythropoietin derivatives prevent motoneuron degeneration in vitro and in vivo. Mol Med 12:153-160.

Mitchell GS (2007) Respiratory plasticity following intermittent hypoxia: a guide for novel therapeutic approaches to ventilatory control disorders. In: Genetic basis for respiratory control disorders (Gaultier C, ed). New York: Springer Publishing.

Mitchell GS, Johnson SM (2003) Neuroplasticity in respiratory motor control. J Appl Physiol 94:358-374.

Mitchell GS, Baker TL, Nanda SA, Fuller DD, Zabka AG, Hodgeman BA, Bavis RW, Mack KJ, Olson EB Jr (2001) Invited review: intermittent hypoxia and respiratory plasticity. J Appl Physiol 90:2466-2475.

Miura Y, Miura O, Ihle JN, Aoki N (1994a) Activation of the mitogenactivated protein kinase pathway by the erythropoietin receptor. J Biol Chem 269:29962-29969.
Miura O, Nakamura N, Ihle JN, Aoki N (1994b) Erythropoietin-dependent association of phosphatidylinositol 3-kinase with tyrosine phosphorylated erythropoietin receptor. J Biol Chem 269:614-620.

Morishita E, Masuda S, Nagao M, Yasuda Y, Sasaki R (1997) Erythropoietin receptor is expressed in rat hippocampal and cerebral cortical neurons, and erythropoietin prevents in vitro glutamate-induced neuronal death. Neuroscience 76:105-116.

Nagańska E, Taraszewska A, Matyja E, Grieb P, Rafałowska J (2010) Neuroprotective effect of erythropoietin in amyotrophic lateral sclerosis (ALS) model in vitro. Ultrastructural study. Folia Neuropathol 48:35-44.

Okutan O, Solaroglu I, Beskonakli E, Taskin Y (2007) Recombinant human erythropoietin decreases myeloperoxidase and caspase-3 activity and improves early functional results after spinal cord injury in rats. J Clin Neurosci 14:364-368.

Opazo P, Watabe AM, Grant SG, O’Dell TJ (2003) Phosphatidylinositol 3-kinase regulates the induction of long-term potentiation through extracellular signal-related kinase-independent mechanisms. J Neurosci 23:3679-3688.

Powell FL, Milsom WK, Mitchell GS (1998) Time domains of the hypoxic ventilatory response. Respir Physiol 112:123-134.

Reichardt LF (2006) Neurotrophin-regulated signaling pathways. Philos Trans R Soc Lond B Biol Sci 361:1545-1564.

Sanchez PE, Fares RP, Risso JJ, Bonnet C, Bouvard S, Le-Cavorsin M, Georges B, Moulin C, Belmeguenai A, Bodennec J, Morales A, Pequignot JM, Baulieu EE, Levine RA, Bezin L (2009) Optimal neuroprotection by erythropoietin requires elevated expression of its receptor in neurons. Proc Natl Acad Sci U S A 106:9848-9853.

Schmidt EK, Fichelson S, Feller SM (2004) PI3 kinase is important for Ras, MEK and ERK activation of Epo-stimulated human erythroid progenitors. BMC Biol 2:7.

Selcher JC, Atkins CM, Trzaskos JM, Paylor R, Sweatt JD (1999) A necessity for MAP kinase activation in mammalian spatial learning. Learn Mem 6:478-490.

Semenza GL, Nejfelt MK, Chi SM, Antonarakis SE (1991) Hypoxiainducible nuclear factors bind to an enhancer element located $3^{\prime}$ to the human erythropoietin gene. Proc Natl Acad Sci U S A 88:5680-5684.

Senger DR, Perruzzi CA, Feder J, Dvorak HF (1986) A highly conserved vascular permeability factor secreted by a variety of human and rodent tumor cell lines. Cancer Res 46:5629-5632.

Shen J, Wu Y, Xu JY, Zhang J, Sinclair SH, Yanoff M, Xu G, Li W, Xu GT (2010) ERK-and Akt-dependent neuroprotection by erythropoietin (EPO) against glyoxal-AGEs via modulation of Bcl-xL, Bax, and BAD. Invest Ophthalmol Vis Sci 51:35-46.

Sirén AL, Knerlich F, Poser W, Gleiter CH, Brück W, Ehrenreich H (2001) Erythropoietin and erythropoietin receptor in human ischemic/hypoxic brain. Acta Neuropathol 101:271-276.

Soliz J, Joseph V, Soulage C, Becskei C, Vogel J, Pequignot JM, Ogunshola O, Gassmann M (2005) Erythropoietin regulates hypoxic ventilation in mice by interacting with brainstem and carotid bodies. J Physiol 568:559-571.

Soliz J, Soulage C, Hermann DM, Gassmann M (2007a) Acute and chronic exposure to hypoxia alters ventilatory pattern but not minute ventilation of mice overexpressing erythropoietin. Am J Physiol Regul Integr Comp Physiol 293:R1702-R1710.

Soliz J, Gassmann M, Joseph V (2007b) Downregulation of soluble erythropoietin receptor in the mouse brain is required for the ventilatory acclimatization to hypoxia. J Physiol 583:329-336.

Spedding M, Gressens P (2008) Neurotrophins and cytokines in neuronal plasticity. Novartis Found Symp 289:222-233; discussion 233-240.

Sui L, Wang J, Li BM (2008) Role of the phosphoinositide 3-kinase-Aktmammalian target of the rapamycin signaling pathway in long-term potentiation and trace fear conditioning memory in rat medial prefrontal cortex. Learn Mem 15:762-776.

Sweatt JD (2004) Mitogen-activated protein kinases in synaptic plasticity and memory. Curr Opin Neurobiol 14:311-317.

Tomioka M, Adachi T, Suzuki H, Kunitomo H, Schafer WR, Iino Y (2006) The insulin/PI 3-kinase pathway regulates salt chemotaxis learning in Caenorhabditis elegans. Neuron 51:613-625.

Trumbower RD, Jayaraman A, Mitchell GS, Rymer WZ (2012) Exposure to acute intermittent hypoxia augments somatic motor function in humans with incomplete spinal cord injury. Neurorehabil Neural Repair 26:163-172. 
Valjent E, Caboche J, Vanhoutte P (2001) Mitogen-activated protein kinase/extracellular signal-regulated kinase induced gene regulation in brain: a molecular substrate for learning and memory? Mol Neurobiol 23:83-99.

Vinit S, Kastner A (2009) Descending bulbospinal pathways and recovery of respiratory motor function following spinal cord injury. Respir Physiol Neurobiol 169:115-122.

Vinit S, Lovett-Barr MR, Mitchell GS (2009) Intermittent hypoxia induces functional recovery following cervical spinal injury. Respir Physiol Neurobiol 169:210-217.

Vitellaro-Zuccarello L, Mazzetti S, Madaschi L, Bosisio P, Gorio A, De Biasi S (2007) Erythropoietin-mediated preservation of the white matter in rat spinal cord injury. Neuroscience 144:865-877.

Vitellaro-Zuccarello L, Mazzetti S, Madaschi L, Bosisio P, Fontana E, Gorio A, De Biasi S (2008) Chronic erythropoietin-mediated effects on the expression of astrocyte markers in a rat model of contusive spinal cord injury. Neuroscience 151:452-466.

Wang GL, Semenza GL (1995) Purification and characterization of hypoxia inducible factor 1. J Biol Chem 270:1230-1237.

Wang GL, Jiang BH, Rue EA, Semenza GL (1995) Hypoxia inducible factor 1 is a basic-helix-loop-helix-PAS heterodimer regulated by cellular O2 tension. Proc Natl Acad Sci U S A 92:5510-5514.

Weber A, Maier RF, Hoffmann U, Grips M, Hoppenz M, Aktas AG, Heinemann U, Obladen M, Schuchmann S (2002) Erythropoietin improves synaptic transmission during and following ischemia in rat hippocampal slice cultures. Brain Res 958:305-311.

Wilkerson JE, Mitchell GS (2009) Daily intermittent hypoxia augments spinal BDNF levels, ERK phosphorylation and respiratory long-term facilitation. Exp Neurol 217:116-123.

Wu CL, Chen SD, Yin JH, Hwang CS, Yang DI (2010) Erythropoietin and sonic hedgehog mediate the neuroprotective effects of brain-derived neurotrophic factor against mitochondrial inhibition. Neurobiol Dis 40:146154.

Xiong Y, Mahmood A, Meng Y, Zhang Y, Qu C, Schallert T, Chopp M (2010) Delayed administration of erythropoietin reducing hippocampal cell loss, enhancing angiogenesis and neurogenesis, and improving functional outcome following traumatic brain injury in rats: comparison of treatment with single and triple dose. J Neurosurg 113:598-608.

Yeo EJ, Cho YS, Kim MS, Park JW (2008) Contribution of HIF- $1 \alpha$ or HIF $2 \alpha$ to erythropoietin expression: in vivo evidence based on chromatin immunoprecipitation. Ann Hematol 87:11-17.

Zhang F, Signore AP, Zhou Z, Wang S, Cao G, Chen J (2006) Erythropoietin protects CA1 neurons against global cerebral ischemia in rat: potential signaling mechanisms. J Neurosci Res 83:1241-1251.

Zhang Y, Xiong Y, Mahmood A, Meng Y, Liu Z, Qu C, Chopp M (2010) Sprouting of corticospinal tract axons from the contralateral hemisphereinto the denervated side of the spinal cord is associated with functional recovery in adult rat after traumatic brain injury and erythropoietin treatment. Brain Res 1353:249-257. 